\title{
Imunossupressão com tacrolimus favorece a regeneração hepática induzida por hepatectomia ampla em ratos
}

\section{Tacrolimus-based immunossupression favours liver regeneration induced by extent hepatectomy in rats}

Ozimo Gama Filho1; Edimar Leandro Toderke, ACBC-PR1; Giorgıo Alfredo Pedroso Baretta, TCBC-PR; Daniele Giacomettı Sakamoto ${ }^{2}$; Miguel Angelo Agulham ${ }^{3}$; Elizabeth Milla Tambara ${ }^{3}$; Jorge Eduardo Fouto Matias, ACBC-PR ${ }^{3}$

\section{RE S U M O}

\begin{abstract}
Objetivo: Avaliar em dois momentos distintos da regeneração hepática a influência do Tacrolimus sobre o fenômeno da regeneração hepática desencadeada pela ressecção de $70 \%$ do parênquima hepático em ratos plenamente desenvolvidos. Métodos: Utilizaram-se 40 ratos Wistar com peso médio de 510,08 g $\pm 11.66 \mathrm{~g}$ distribuidos aleatoriamente em dois grupos de 20, cada grupo subdividido em dois subgrupos conforme o dia da morte após a hepatectomia. De acordo com o grupo os animais receberam por gavagem solução aquosa de Tacrolimus $0,1 \mathrm{mg} / \mathrm{kg} / \mathrm{dia}$ ou solução salina no mesmo volume. Após três dias de pré-terapia todos foram submetidos à hepatectomia de $70 \%$ pela ressecção dos lobos hepáticos mediano e lateral esquerdo que foram pesados para posterior cálculo da regeneração hepática pela fórmula de Kwon. Vinte e quatro horas ou sete dias após a hepatectomia, 10 animais de cada grupo foram mortos, os fígados remanescentes (regenerados) foram pesados e amostrados para realização de índice mitótico por hematoxilina-eosina e estudo imunoistoquímico com os marcadores PCNA e Ki-67. Resultados: Os animais que receberam tacrolimus mostraram índice maior de regeneração hepática, atingindo significância estatística quando comparado ao subgrupo de animais mantidos com placebo quando analisados pelos parâmetros: fórmula de Kwon, índice mitótico e marcador PCNA. A tendência para o marcador Ki-67 foi idêntica aos outros parâmetros mas não alcançou significância estatística. Conclusão: A imunossupressão com tacrolimus possui efeito estimulatório no processo de regeneração hepática desencadeado pela hepatectomia $70 \%$ em ratos Wistar adultos, plenamente desenvolvidos.
\end{abstract}

Descritores: Tacrolimus. Hepatectomia. Regeneração hepática.

\section{INTRODUÇÃO}

\begin{abstract}
A regeneração hepática representa o resultado de respostas fisiológicas que ocorrem após perdas de parênquima, como conseqüência de agressões tóxicomedicamentosas, infecciosas, traumáticas ou cirúrgicas'.

O fígado possui reserva funcional e capacidade regenerativa consideráveis. Porém este crescimento tecidual se constitui em um fenômeno complexo, do qual participam hormônios e substâncias presentes no soro, ou secretadas nos próprios tecidos após estímulo adequado².

Apesar de ser largamente utilizado, o termo "regeneração" é biologicamente incorreto, uma vez que a resposta induzida pelo dano tecidual hepático promove hiperplasia e hipertrofia compensatória do tecido remanescente, até o restabelecimento da massa hepática inicial. Logo os lóbulos ressecados ou destruídos não são recuperados $^{2}$. Todas as células hepáticas remanescentes prolife-
\end{abstract}

ram para substituir a perda de tecido hepático e após a reestruturação do parênquima o processo regenerativo ces$\mathrm{sa}^{3}$.

A cirrose é uma doença crônica do fígado decorrente de destruição e regeneração das células hepáticas, que acarreta, do ponto de vista histológico, a presença de fibrose e a transformação nodular difusa, com conseqüente desorganização das arquiteturas lobular e vascular do órgão, capaz de impor graus proibitivos de disfunção orgânica, atingindo estádios irreversíveis de insuficiência.

Em 1983 o Instituto Nacional de saúde Americano declarou o transplante hepático modalidade terapêutica aceitável clinicamente para pacientes com doença hepática terminal ${ }^{4}$.

Devido à relevância dos fenômenos regenerativos no fígado transplantado e a possibilidade de interferência de múltiplos fatores, quer endógenos quer exógenos, surge o interesse pela definição de que tipo de ação drogas

Trabalho realizado no Laboratório de Cirurgia Experimental do Programa de Pós-Graduação em Clínica Cirúrgica da UFPR, como parte integrante da dissertação de Mestrado do aluno Ozimo Gama Filho no Programa de Pós-Graduação em Clínica Cirúrgica da UFPR- Curitiba - BR. 1. Mestrandos do Programa de Pós-Graduação em Clínica Cirúrgica da Universidade Federal do Paraná - UFPR- Curitiba - BR; 2. Patologista Curitiba - PR-BR; 3. Professores Adjunto do Departamento de Cirurgia da UFPR; Docentes do Programa de Pós-Graduação em Clínica Cirúrgica da UFPR-BR. 
imunossupressoras teriam sobre a regeneração hepática, pois tais drogas constituem a base do tratamento após transplante de órgãos sólidos.

Os inibidores da calcineurina, cujos representantes são a ciclosporina A e o tacrolimus (FK 506), são os agentes imunossupressores mais utilizados atualmente em pacientes submetidos a transplante hepático cadavérico ou inter-vivos. A calcineurina é uma fosfatase cálcio-dependente responsável pele transcrição da interleucina 2 (IL-2), principal citocina envolvida na resposta imunológica mediada pelo linfócito T. As drogas agem, portanto, inibindo a produção de IL-2, bloqueando desta forma os mecanismos envolvidos na rejeição celular aguda 5 .

Francavilla et al. ao estudarem os efeitos do tacrolimus na resposta regenerativa em ratos submetidos á hepatectomia $70 \%$, demonstraram que esta droga apresenta efeito positivo provavelmente por uma via não imunológica por inibição da apoptose dos hepatócitos em regeneração e por uma via imunológica através da inibição das células "natural killer" que apresentam efeito citotóxico direto nos sinusóides hepáticos ${ }^{6,7}$.

Considerando-se a importância do estudo do efeito dos inibidores da calcineurina, em especial do tacrolimus, sobre a regeneração e remodelação do parênquima hepático, justifica-se o interesse pela análise dos efeitos deste imunossupressor sobre o fenômeno de regeneração hepática quando induzida experimentalmente em ratos através da ressecção de $70 \%{ }^{8}$.

O presente estudo visou avaliar, em dois momentos distintos da regeneração hepática, a influência do Tacrolimus sobre o fenômeno da regeneração hepática desencadeada pela ressecção de $70 \%$ do parênquima hepático em ratos plenamente desenvolvidos.

\section{MÉTODOS}

O projeto de pesquisa do presente estudo foi realizado de acordo com as normas éticas estabelecidas pelo Colégio Brasileiro de Experimentação Animal (COBEA) e Lei Federal 6638, submetido, analisado e aprovado pelo Comitê de Ética em Pesquisa do Setor de Ciências da Saúde da UFPR (CEP/SD), sob o registro CEP/SD: AN.008.004.07.08. Foram utilizados 40 ratos Wistar (Rattus norvegicus albinus, Roentia mammalia) adultos, machos, provenientes do biotério de criação do Instituto Politécnico da Universidade Federal do Paraná (UFPR). O peso médio inicial dos animais foi 510,08 g (DP \pm 11.66), variando entre $424 \mathrm{~g}$ e $559,8 \mathrm{~g}$.

O experimento foi realizado no Laboratório de Cirurgia Experimental do Programa de Pós-Graduação em Clínica Cirúrgica da UFPR, onde durante todo o período de estudo os animais permaneceram em ambiente com controle de temperatura $\left(22 \pm 1^{\circ} \mathrm{C}\right)$, ruído e luminosidade (ciclos claro-escuro de 12 horas - Cronomat ${ }^{\circledR}$, Mallory do Brasil, São Paulo, SP, Brasil), agrupados em número máxi- mo de cinco, em gaiolas coletivas de aproximadamente $0,022 \mathrm{~m}^{3}(41,4 \mathrm{~cm} \times 34,4 \mathrm{~cm} \times 16 \mathrm{~cm})$. As gaiolas, em número total de 10 , foram identificadas e acomodadas sobre estantes horizontais. Durante todo o período de aclimatação (14 dias), e de estudo, os animais receberam água e ração balanceada ad libitum, padrão Nuvilab $C R 1^{\circledR}$, produzido pela empresa Nuvital Nutrientes, Colombo, PR, Brasil. Os animais foram pesados e divididos aleatoriamente em dois grupos de 20 ratos. Cada um desses grupos foi subdividido em dois subgrupos conforme a medicação utilizada e o dia da morte:

Grupo de Estudo (E): constituído por 20 animais que receberam Tacrolimus do terceiro dia pré-operatório até a morte, subdividindo-se em:

a) E.24h: constituído por 10 animais que receberam Tacrolimus do terceiro dia pré-operatório até a morte 24 horas após a hepatectomia;

b) E.7d: constituído por 10 animais que receberam Tacrolimus do terceiro dia pré-operatório até a morte sete dias após a hepatectomia;

Grupo Controle (C): constituído por 20 animais que receberam solução salina isotônica (SSI) à $0,9 \%$ do terceiro dia pré-operatório até a morte, subdividindo-se em:

a) C.24h: constituído por 10 animais que receberam SSI à 0,9\% do terceiro dia pré-operatório até a morte 24 horas após a hepatectomia;

b) C.7d: constituído por 10 animais que receberam SSI à 0,9\% do terceiro dia pré-operatório até a morte sete dias após a hepatectomia.

A pesagem dos animais foi diária, em balança modelo AM 500 Marte $^{\circledR}$, regulada nos padrões do Inmetro e usada para calcular a dose diária da medicação em estudo em relação a variação do peso corporal.

Para administração diária por gavagem do imunossupressor ou de SSI à 0,9\% (placebo), os animais foram submetidos à anestesia inalatória com vaporizador de isoflurano (Isoforine ${ }^{\circledR}$ - laboratório Cristália) na concentração de 1,5 a 3\% e fluxo de oxigênio variando de 0,5 a 3L/min. Cápsulas de Tacrolimus 1 mg (JANSSEN- CILAG, São Paulo, SP, Brasil) foram foram abertas e seu conteúdo diluído em solução aquosa até a dosagem de $1 \mathrm{mg} / \mathrm{ml}$. Dose padronizada de $0,1 \mathrm{mg} / \mathrm{kg} /$ dia foi fornecida via sondagem orogástrica rígida aos animais dos grupos E.24h e E.7d. Nos grupos controle, utilizou-se quantidades isovolumétricas de SSI à 0,9\% (Baxter, São Paulo, SP, Brasil).

Após três dias de administração orogástrica de Tacrolimus ou placebo de acordo com grupo e subgrupo, todos os animais submeteram-se - após anestesia já acima descrita, tricotomia e antissepsia da região ventral com solução tópica de polivinilpirrolidona-iodo (PVPI) - à ressecção cirúrgica de $70 \%$ da massa hepática total. O procedimento cirúrgico consistiu em realizar a laparotomia mediana longitudinal de $4 \mathrm{~cm}$ a partir do apêndice xifóide; abertura por planos; liberação dos ligamentos hepáticos; ligadura única dos pedículos dos lobos lateral esquerdo e 
mediano do fígado com monocril 3-0 e ressecção da massa hepática referente aos dois lobos (Figura 1).

O fechamento da laparotomia foi realizado com sutura contínua única de prolene 3-0. O espécime ressecado foi pesado para posterior cálculo da regeneração hepática pela fórmula de Kwon e em seguida desprezado.

Após 24 horas da hepatectomia, 10 animais do subgrupo E.24h e 10 do subgrupo C.24h foram submetidos à morte por dose letal inalatória de éter etílico em campânula de vidro. Em seguida o rato foi pesado, posicionado em mesa cirúrgica e, através da reabertura da incisão, inspecionou-se o fígado remanescente regenerado, realizou-se a liberação cuidadosa de todo o órgão e secção das veias supra-hepáticas, porta e cava inferior. O fígado retirado foi pesado e, para estudo histológico, foi amostrada a porção superior do lobo direito, a qual foi armazenada em solução de formalina 10\% (Rioquímica, São José do Rio Preto, SP, Brasil).

Após sete dias da hepatectomia, os mesmos procedimentos descritos acima foram executados em 10 animais do subgrupo E.7d e 10 do subgrupo C.7d, para completar-se a amostragem de todos os quatro subgrupos do estudo.

Análise da Regeneração Hepática pelo peso Hepático (Fórmula de Kwon)

Logo após a morte dos animais, calculou-se a regeneração hepática de cada grupo pela fórmula de Kwon ${ }^{9}$, a qual fornece a taxa de regeneração baseada no peso hepático:

Onde: $\%$ de Regeneração Hepática $=$ D/E x 100

$\mathrm{D}=$ peso do fígado por 100 gramas de peso do animal no dia da morte;
$\mathrm{E}=$ estimativa do peso do fígado por 100 gramas de peso do animal no dia da hepatectomia, a qual é calculada a partir do peso do fígado ressecado durante a hepatectomia $(R)$. Onde $E=R / 0,7$.

\section{Análise da Regeneração Hepática pelo Índice Mitótico (HE) \\ O estudo histológico com coloração de} Hematoxilina-Eosina foi desenvolvido no Laboratório de Anatomia Patológica do Hospital de Clínicas da UFPR. Para avaliação da regeneração hepática utilizando-se o índice mitótico, um fragmento da porção superior do lobo direito após a morte de cada animal foi colocado em frasco contendo formalina $10 \%$. As amostragens macroscópicas foram padronizadas para todos os espécimes, realizando-se cortes transversais na porção média do fragmento hepático. Após desidratação, diafanização e emblocamento dos tecidos em parafina, foram realizadas microtomias de 4 $\mu \mathrm{m}$ e coloração com Hematoxilina-Eosina. Analisaram-se 10 campos de grande aumento (400X) de maneira aleatória, sendo as figuras de mitose registradas e fotografadas.

\section{Análise da Regeneração Hepática pela Imunoistoquímica com PCNA}

O estudo imunoistoquímico com PCNA foi desenvolvido no Laboratório de Anatomia Patológica do Hospital de Clínicas da UFPR. Foram utilizadas lâminas silanizadas para evitar o descolamento dos cortes histológicos durante a coloração. As peças foram desparafinizadas e reidratadas em concentrações adequadas de etanol e água destilada. A atividade da peroxidase endógena foi bloqueada com a utilização de água oxige-
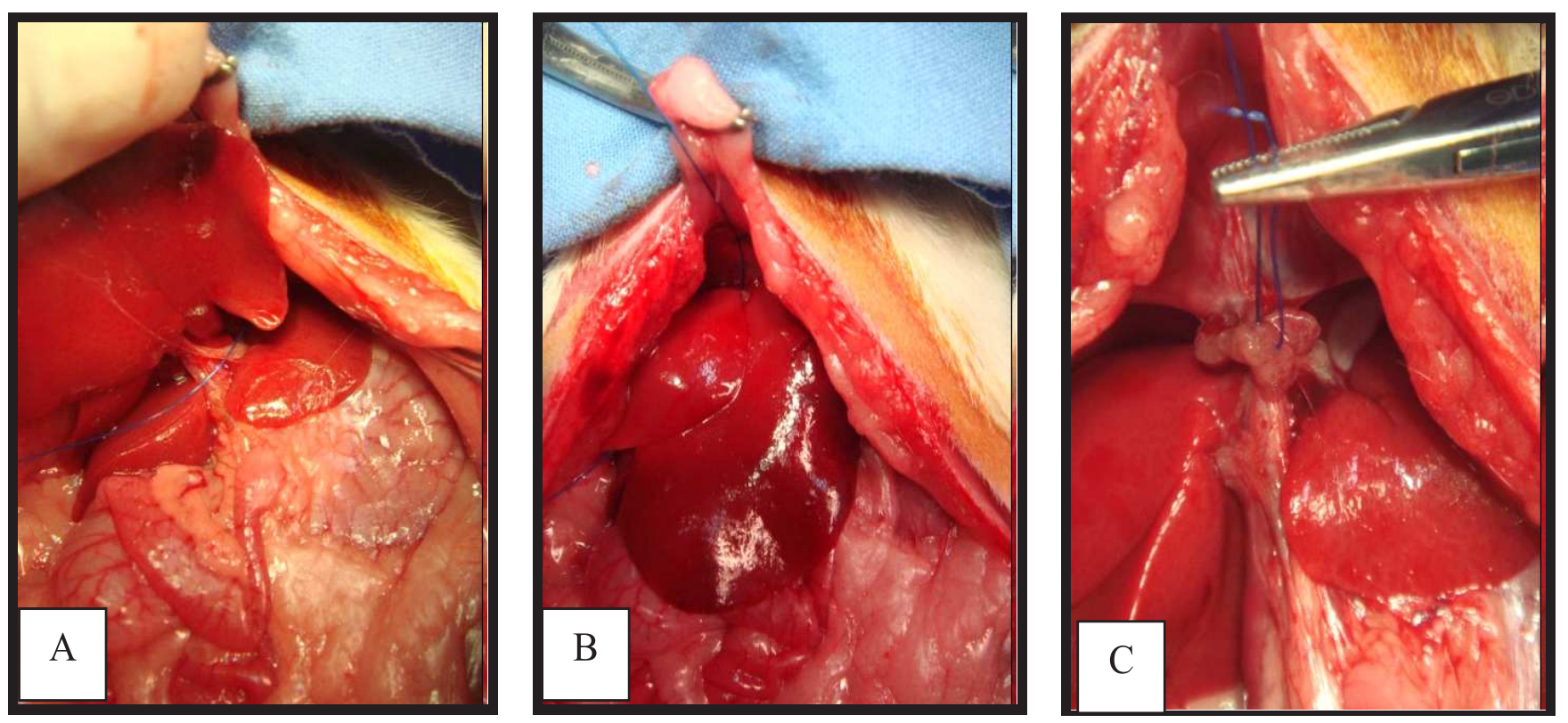

Figura 1 - Procedimento cirúrgico: (A) Fio passado ao redor dos pedículos dos lobos lateral esquerdo e mediano; (B) Visão frontal após ligadura ainda sem ressecção; (C) Aspecto final após retirada dos lobos perfazendo 70\% da massa hepática. 
nada $\left(\mathrm{H}_{2} \mathrm{O}_{2}\right)$ a $3 \%$ por cinco minutos, seguido por uma breve rinsagem em água destilada e lavagem de 15 minutos em PBS. As peças foram então colocadas em um tampão de citrato com pH de 6,0 e então aquecidas em forno de microondas a $98^{\circ} \mathrm{C}$ por cinco minutos para o PCNA. Após, as peças foram resfriadas à temperatura ambiente por 20 minutos e rinsadas em PBS. Anticorpos primários anti-PCNA (Monoclonal, Código M0879, Dako, Carpinteria, USA) foram aplicados "overnight" à temperatura de $2^{\circ} \mathrm{C}$ a $8^{\circ} \mathrm{C}$. Após banho em tampão fosfato, seguiu-se à aplicação de anticorpo biotinilado por 30 minutos, à temperatura ambiente. Após novo banho em tampão fosfato, seguiu-se à aplicação do complexo estreptavidina peroxidase por 30 minutos, ainda à temperatura ambiente. Foi então realizado mais um banho em tampão fosfato e revelação da reação imune com Diaminobenzidina, seguido de contra-coloração com Hematoxilina. Na seqüência , os cortes foram desidratados e montados com bálsamo e lamínulas de vidro.

A positividade da coloração imunoistoquímica foi identificada nas áreas de pigmentação acastanhada. Controles positivos e negativos foram utilizados. As lâminas foram avaliadas sem a identificação dos grupos dos animais. Foram analisados 100 hepatócitos de maneira aleatória e considerados positivos os que coraram-se moderada ou fortemente e, deste modo, efetuada a porcentagem de células positivas.

\section{Análise da Regeneração Hepática pela Imunoistoquímica com Ki-67 \\ O estudo imunoistoquímico foi desenvolvido no} Laboratório de Anatomia Patológica do Hospital de Clínicas da UFPR. Foram utilizadas lâminas silanizadas para evitar o descolamento dos cortes histológicos durante a coloração. As peças foram desparafinizadas e reidratadas em concentrações adequadas de etanol e água destilada. A atividade da peroxidase endógena foi bloqueada com a utilização de água oxigenada $\left(\mathrm{H}_{2} \mathrm{O}_{2}\right)$ a $3 \%$ por cinco minutos, seguido por uma breve rinsagem em água destilada e lavagem de 15 minutos em PBS. As peças foram então colocadas em um tampão de citrato com pH de 6,0 e então aquecidas em forno de microondas a $98^{\circ} \mathrm{C}$ por 30 minutos para o Ki-67. Após, as peças foram resfriadas à temperatura ambiente por 20 minutos e rinsadas em PBS. Anticorpos primários anti-Ki67 (Monoclonal, Código NCLKi-67-MM1, Clone MM1, Novocastra, USA) foram aplicados "overnight" à temperatura de $2^{\circ} \mathrm{C}$ à $8^{\circ} \mathrm{C}$. Após banho em tampão fosfato, seguiu-se à aplicação de anticorpo biotinilado por 30 minutos, à temperatura ambiente. Após novo banho em tampão fosfato, seguiu-se à aplicação do complexo estreptavidina - peroxidase por 30 minutos, ainda à temperatura ambiente. Foi então realizado mais um banho em tampão fosfato e revelação da reação imune com Diaminobenzidina, seguido de contra-coloração com Hematoxilina. Na seqüência, os cortes foram desidratados e montados com bálsamo e lamínulas de vidro.
A positividade da coloração imunoistoquímica foi identificada nas áreas de pigmentação acastanhada. Controles positivos e negativos foram utilizados. As lâminas foram avaliadas sem a identificação dos grupos dos animais. Foram analisados 100 hepatócitos de maneira aleatória e considerados positivos os que coraram-se moderada ou fortemente e, deste modo, efetuada a porcentagem de células positivas.

\section{Análise Estatística}

Todos os dados foram tabulados em planilha do programa Microsoft Office Exce ${ }^{\circledR}$ (Microsoft Corporation, Redmond, WA, EUA), obtendo-se os valores médios ( $M$ ), mediana, desvio padrão (DP) para cada variável nos diferentes tempos estudados.

Procedeu-se ao tratamento estatístico conforme a natureza dos dados analisados nos grupos controle e estudo, nos períodos 24 horas e sete dias. Observou-se o pré-requisito da distribuição normal (Gaussiana) das variáveis para a escolha do teste estatístico. Na análise não-paramétrica foi utilizado o teste de Mann-Whitney para as comparações do peso total estimado do fígado (g) no dia da hepatectomia e do peso do animal (g) no mesmo momento entre os grupos nos períodos 24 horas e sete dias; relação do peso total do fígado (g) no dia da morte e do peso do animal (g) no mesmo momento no período 24 horas; porcentagem do Ki67 dentro do grupo estudo e entre os grupos no período sete dias; porcentagem do índice mitótico entre os grupos no período 24 horas. Nos demais resultados utilizou-se a análise paramétrica com o teste " $t$ " de Student. Para todos os testes estatísticos o nível de significância adotado foi de $5 \%(p=0,05)$

\section{RESULTADOS}

\section{gado - Fórmula de Kwon}

A regeneração hepática avaliada pela fórmula de Kwon mostrou crescimento estatisticamente significativo do remanescente hepático nos dois grupos (estudo/controle), nas primeiras 24 horas e no sétimo dia póshepatectomia.(Figura 2). Quando pareados os resultados intergrupos, os animais que receberam tacrolimus mostraram índice maior de regeneração hepática, atingindo significância estatística quando comparado ao subgrupo de animais mantidos com placebo (Figura 3).

\section{Regeneração Hepática pelo Índice Mitótico}

$\mathrm{Na}$ avaliação do índice mitótico pela coloração de Hematoxilina-Eosina ( $\mathrm{HE})$, a diferença estatística foi observada no grupo controle entre os dois períodos $(p=0,01)$ e também no grupo de estudo entre os mesmos períodos, porém com maior diferença quando comparados intergrupos (Figura 4). 


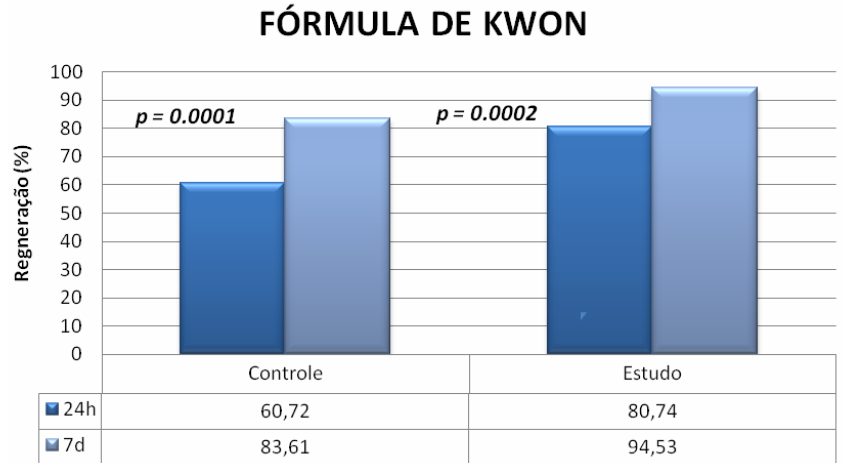

Figura 2 - Porcentagem de regeneração hepática pela fórmula de kwon. comparações estatísticas intragrupos (24h $x 7 d)$.

\section{FÓRMULA DE KWON}

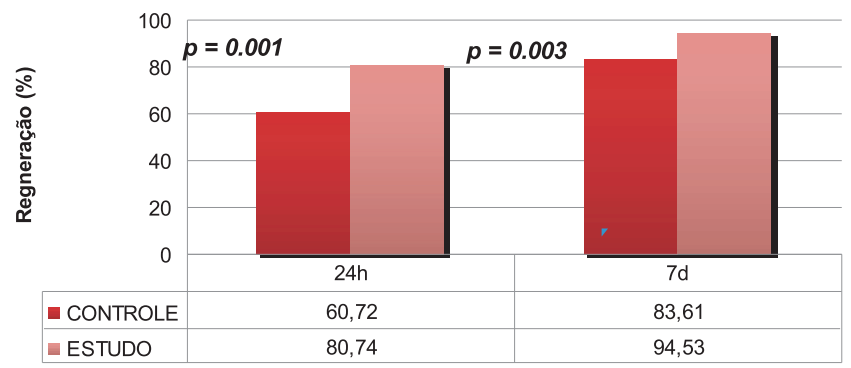

Figura 3 - Porcentagem da regeneração hepática pela fórmula de kwon. Comparações estatísticas intergrupos (controle $x$ estudo).

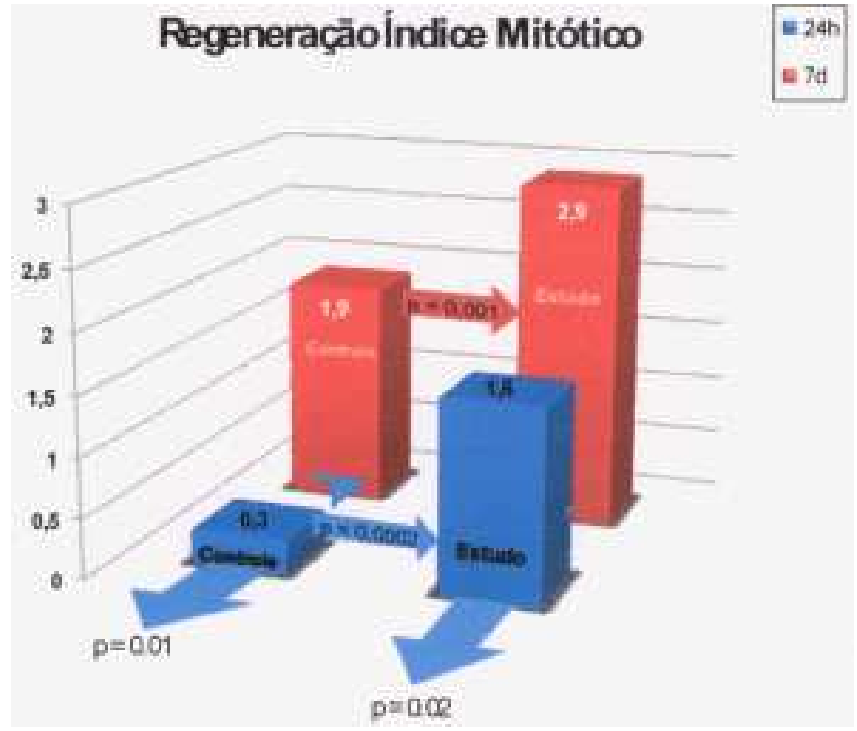

Figura 4 - Avaliação da regeneração hepática pelo índice mitótico. Comparações estatísticas intra e intergrupos.

\section{com PCNA}

Regeneração Hepática pela Imunoistoquímica

Com relação ao anticorpo, o PCNA, observouse diferença estatística entre os grupos controle e estudo nos dois períodos, porém sem diferença intragrupos (Tabela 1).

\section{com Ki-67}

Regeneração Hepática pela Imunoistoquímica

Com relação ao antígeno Ki-67, a análise estatística dentro e entre os grupos controle e de estudo nos períodos de 24 horas e sete dias não foram encontradas diferenças estatisticamente significativas (Tabela 2).

\section{DISCUSSÃO}

O processo de regeneração hepática compreende um intrincado mecanismo molecular, celular e genético auto-regulado com marcadores de iniciação e finalização que apresenta como objetivo final a reconstituição da funcionalidade hepática utilizando múltiplas vias de sinalização ${ }^{10}$.

O modelo universalmente utilizado para o estudo experimental deste fenômeno é a realização de hepatectomia à $70 \%$ em roedores proposta por Higgins e Anderson ${ }^{11}$. Neste modelo, os pesquisadores costumam utilizar ratos Wistar jovens, com pesos até $250 \mathrm{~g}$, o que faz a resposta de regeneração ser de tal exuberância que chega a atingir níveis acima de $100 \%$ nos parâmetros normalmente avaliados ${ }^{12,13}$. Acreditamos que nas condições de estudo acima descritas a regeneração hepática se apóia, pelo menos parcialmente, e sofre influência de múltiplos fatores presentes e ativos nos animais jovens em fase de crescimento. Neste estudo utilizamos propositalmente ratos Wistar adultos, plenamente desenvolvidos, com pesos acima de 400 gramas, na tentativa de obtermos como único estímulo e fator interveniente para a regeneração hepática a ressecção extensa do parênquima hepático e o uso do tacrolimus respectivamente.

Já na década de 80 foi demonstrada a capacidade de estímulo do Tacrolimus na regeneração hepática ${ }^{6}$. A larga utilização desta droga nos esquemas de imunossupressão pós transplante hepático e o aumento do número de transplante utilizando a técnica de doador vivo ou intervivos demonstra a importância do estudo da participação do Tacrolimus na regeneração hepática.

Nossa metodologia incluiu a pré-terapia com Tacrolimus por três dias consecutivos antes do estímulo à regeneração hepática (ressecção de $70 \%$ do fígado), o que certamente difere do uso clínico normal deste imunossupressor em humanos. Porém, como o fenômeno de regeneração hepática em ratos após hepatectomia à $70 \%$ é bastante conhecido e se caracteriza por apresentar a maioria das alterações moleculares e celulares já nas primeiras 24 a 48 horas após a ressecção', achamos altamente conveniente que os animais já estivessem com níveis sanguíneos do imunossupressor quando se submetessem ao estímulo da regeneração hepática.

Como não monitoramos os níveis séricos do imunossupressor durante o estudo, a administração do fármaco através de gavagem, desde o terceiro dia préoperatório até a morte dos animais em 24 horas ou sete 
Tabela 1 - Análise estatística das médias da porcentagem do pcna intra e intergrupos nos períodos 24 horas e sete dias.

\begin{tabular}{|c|c|c|c|c|c|c|}
\hline \multirow[t]{2}{*}{ Grupos } & & & \multicolumn{3}{|c|}{ Porcentagem do PCNA } & \multirow[t]{2}{*}{$p$} \\
\hline & & & média $\pm d p$ & $x$ & média $\pm d p$ & \\
\hline Controle 24 horas & $x$ & Controle 7 dias & $67,4 \pm 17,6$ & $x$ & $57,9 \pm 22,2$ & 0,20 \\
\hline Estudo 24 horas & $x$ & Estudo 7 dias & $80,7 \pm 5,1$ & $x$ & $78,5 \pm 18,95$ & 0,36 \\
\hline Controle 24 horas & $x$ & Estudo 24 horas & $67,4 \pm 17,6$ & $x$ & $80,7 \pm 5,1$ & 0,01 \\
\hline Controle 7 dias & $x$ & Estudo 7 dias & $57,9 \pm 22,2$ & $x$ & $78,5 \pm 18,95$ & 0,01 \\
\hline
\end{tabular}

Nota: $d p$ - desvio-padrão, $p$ - nível de significância estatística.

Tabela 2 - Análise estatística das médias da porcentagem do ki67 intra e intergrupos nos períodos 24 horas e sete dias.

\begin{tabular}{lllcccc}
\hline Grupos & & & \multicolumn{2}{c}{ Porcentagem do Ki67 } & p \\
\cline { 3 - 6 } & & & média \pm dp & x & média \pm dp \\
\hline Controle 24 horas & $\mathrm{x}$ & Controle 7 dias & $58,3 \pm 19,8$ & $\mathrm{x}$ & $44,7 \pm 18,0$ & 0,12 \\
Estudo 24 horas & $\mathrm{x}$ & Estudo 7 dias & $68,8 \pm 10,93$ & $\mathrm{x}$ & $64,8 \pm 26,51$ & 0,34 \\
Controle 24 horas & $\mathrm{x}$ & Estudo 24 horas & $58,3 \pm 19,8$ & $\mathrm{x}$ & $68,8 \pm 10,93$ & 0,07 \\
Controle 7 dias & $\mathrm{x}$ & Estudo 7 dias & $44,7 \pm 18,0$ & $\mathrm{x}$ & $64,8 \pm 26,51$ & 0,08 \\
\hline
\end{tabular}

dias após a ressecção hepática, assegurou o aporte da dose de $0,1 \mathrm{mg} / \mathrm{Kg} / \mathrm{dia}$, levando sempre em consideração a variação do peso corpóreo aferido diariamente para este fim.

Foram aferidas as médias do peso do fígado ressecado, a massa restante e o peso total do órgão no momento da hepatectomia e da morte. Ocorreu diferença significativa nos subgrupos 24 horas o que pode demonstrar o início de ação precoce do Tacrolimus no processo de cicatrização ${ }^{14,15}$

No presente trabalho quando comparamos os valores da regeneração pela fórmula de Kwon dentro de cada grupo, observamos aumento significativo da taxa de regeneração no grupo controle, sendo o mesmo tipo de resultado obtido com o grupo de estudo porém com um aumento ainda mais pronunciado $(p<0,01)$.

Este aumento progressivo é ocasionado por dois picos de mitoses encontrados normalmente durante o processo de regeneração. O primeiro ocorre dentro de 24 horas após a hepatectomia e é devido exclusivamente aos hepatócitos ${ }^{2}$.

No segundo pico de mitoses há à participação das células não-parenquimatosas, nos ratos ocorre dentro de 72 horas, sendo mais evidente nas hepatectomias maiores que $50 \%$ do parênquima e avaliadas após sete dias ${ }^{3}$.

A taxa de regeneração hepática foi avaliada também pelo índice mitótico e análise imunoistoquímica com marcadores PCNA e Ki-67. O índice mitótico avalia o número de hepatócitos em processo de mitoses corados no HE com aumento de 400 vezes.

Em nosso estudo observamos diferença estatística tanto inter quanto intragrupos na avaliação do índice mitótico. Estas aumentaram cronologicamente, levandonos a considerar que quanto mais tempo sob ação do
Tacrolimus maior o efeito positivo na regeneração hepática, assim como demonstrado por outros autores ${ }^{16-18}$.

Alvira et al. ${ }^{19}$ demonstraram que a ação dos imunossupressores, em especial os inibidores da calcineurina, em porcos transplantados são dose - dependentes em relação ao efeito hepatotrófico. Sendo esta característica reproduzida tanto nas hepatectomias quanto nos enxertos de "split liver" 20 .

Quando avaliamos a regeneração hepática pelo PCNA, proteína que expressa atividade do ciclo celular (transição G1 / S), encontramos diferença estatística na avaliação intergrupos o que demonstra a facilitação da passagem das células parenquimatosas e não-parenquimatosas devido a ação do Tacrolimus.

Francavilla et al. ${ }^{8}$ demonstrou que o Tacrolimus atua como fator de crescimento isolado facilitando a fase de priming da regeneração, além de reduzir o stress isquêmico celular ${ }^{21}$ e modular a resposta inflamatória de forma positiva ${ }^{14}$.

O Ki-67 é um antígeno nuclear expresso nas fases G1, S, G2 e M do ciclo celular. Seu índice (percentual de células marcadas/total de células avaliadas) é utilizado para quantificar a atividade proliferativa celular ${ }^{22}$. Em nosso estudo o marcador Ki-67 falhou em demonstrar maior proliferação hepatocitária nos subgrupos tratados com tacrolimus, apesar de uma clara tendência estatística no mesmo sentido dos outros parâmetros do estudo.

Como a proteína Ki-67 está localizada no núcleo celular, em especial no nucléolo, acreditamos que a ação do Tacrolimus em níveis genéticos necessitam de avaliação em tempo mais prolongado que sete dias para definirmos a parcela de interferência neste mecanismo por mecanismos transcripicionais ${ }^{23,24}$. 
Os dados do presente estudo comprovam o efeito estimulatório do Tacrolimus sobre o fígado em processo de regeneração desencadeado por ressecção extensa do parênquima hepático no decorrer dos sete dias de observação.
Outras pesquisas devem ser realizadas no sentido de elucidar todos os mecanismos celulares e moleculares envolvidos neste fenômeno, o que certamente traria potenciais benefícios ainda não explorados na utilização clínica atual desta farmacoterapia.

\section{A B S T R A C T}

Objective: To analyze, during two different moments of liver regeneration, the effect of the immunosuppressant Tacrolimus on the $70 \%$ hepatectomy model-induced liver regeneration in adult rats. Methods: Forty Wistar adult rats, weighing $510.08+11.66$ $g$ were randomly divided into two groups, each group divided into two subgroups according to the death day after $70 \%$ hepatectomy . According to the group of study, rats received $0.1 \mathrm{mg} / \mathrm{Kg} /$ day of Tacrolimus or the same volume of saline solution, by gavage. After three days of pre-therapy, all animals were submitted to $70 \%$ hepatectomy by resection of median and left lateral hepatic lobes which were weighed for posterior calculation of liver regeneration by Kwon's formula. Twenty four hours or seven days after hepatectomy ten rats of each group were killed; the remaining liver (regenerated) was entirely resected, weighed and sampled for mitotic index on hematoxylin-eosin staining and immunohistochemical assays with PCNA and Ki-67 markers. Data were statistically analyzed by Mann-Whitney or Student " $t$ " tests, with significance level of 5\% ( $p<0.05)$. Results: Rats receiving tacrolimus showed statistically significant higher levels of liver regeneration when compared to placebo according to Kwon's formula, mitotic index and PCNA marker. Identical trend was found with Ki-67 marker, but without statistical significance. Conclusion: Tacrolimus-based immunossuppression has stimulatory effect on liver regeneration process induced by $70 \%$ hepatectomy in adult Wistar rats.

Key words: Tacrolimus. Hepatectomy. Liver regeneration.

\section{REFERENCIAS}

1. Fausto N. Liver regeneration and repair: hepatocytes, progenitor cells, and stem cells. Hepatology. 2004; 39(6): 1477-87.

2. Fausto N, Riehle KJ. Mechanisms of liver regeneration and their clinical implications. J Hepatobiliary Pancreat Surg. 2005; 12(3):1819

3. Koniaris LG, McKillop IH, Schwartz SI, Zimmers TA. Liver regeneration. J Am Coll Surg. 2003; 197(4):634-59.

4. National Institute of Health Conference. Hepatology 1984; 4; 51

5. Schreiber SL. The mechanism of action of cyclosporin A and FK506. Immunol Today. 1992; 13(4):136-42.

6. Francavilla A, Barone $M$, Todo S, Zeng QH, Porter KA, Starzl TE. Augmentation of rat liver regeneration by FK506 compared with cyclosporin. Lancet. 1989; 2(8674):1248-9.

7. Francavilla A, Starzl TE, Barone M, Zeng QH, Porter KA, Zeevi A et al. Studies on mechanisms of augmentation of liver regeneration by ciclosporine and FK506. Hepatology. 1991; 14(1): 140-3.

8. Francavilla $A$, Barone $M$, Starzl TE, Zeevi A, Scotti C, Carrieri G et al. FK 506 as a growth control factor. Transplant Proc. 1990; 22(1): $90-2$.

9. Kwon AH, Uetsuji S, Yamamura M, Hioki K, Yamamoto M. Effect of administration of fibronectin or aprotimin on liver regeneration after experimental hepatectomy. Ann Surg. 1990; 211( 3): 295300.

10. Fausto N, Campbell JS, Riehle KJ. Liver regeneration. Hepatology. 2006; 43(2 Suppl 1): S45-53.

11. Higgins G, Anderson R. Experimental pathology of the liver. Restoration of the liver of the white rat following partial surgical removal. Arch Pathol. 1931; 12(1):186-202.

12. Biondo-Simões ML, Matias JE, Montibeller GR, Siqueira LC, Nunes Eda S, Grassi CA. Effect of aging on liver regeneration in rats. Acta Cir Bras 2006; 21(4):197-202.

13. Tannuri AC, Tannuri U, Wakamatsu A, Mello ES, Coelho MC, dos Santos NA. Effect of the immunosuppressants on hepatocyte cells proliferation and apoptosis in young animal model of liver regeneration. Pediatr Tranplant. 2008; 12(1):40-6.
14. Granelli-Piperno A, Nolan P, Inaba K, Steinman RM. The effect of imunosupressive agents on the induction of nuclear factors that bind to sites on interleukin-2 promoter. J Exp Med. 1990; 172(6): 1869-72.

15. Lodewjik L, Mall A, Spearman CW, Kahn D. Effect of liver regeneration on the pharmacokinetics of immu-nosuppressive drugs. Transplant Proc. 2009; 41(1): 379-81.

16. Kaibori M, Inoue T, Tu W, Oda M, Kwon AH, Kamiyama Y, Okumura T. FK 506, but not cyclosporin A, prevents mitochondrial dysfunction during hypoxia in rat hepatocytes. Life Sci 2001; 69(1):17-26.

17. Kawano K, Bowers JL, Kim Yl, Tatsuma T, Kitano S, Kobayashi M, Clouse ME. FK 506 reduces oxidative hepatic injury following cold ischemic preservation and transplantation. Transplant Proc. 1996; 28(3):1902-3

18. Mazzaferro V, Scotti-Foglieni CL, Porter KA, Trejo Bellido J, Carrieri $\mathrm{G}$, Todo $\mathrm{S}$ et al. Studies of the hepatotrophic qualities of FK506 and CyA. Transplant Proc. 1990; 22(1): 93-5.

19. Alvira LG, Herrera N, Salas C, Pereira F, Herrera J, Suárez-Massa $M D$, Castillo-Olivares JL. Influence of cyclosporine on graft regeneration and function after liver transplantation: trial in pigs. Transplant Proc. 2002; 34(1): 315-6.

20. Dahmen U, Gu YL, Shen K, Dirsch O, Li J, Fan LM, Broelsch C. Onset of liver regeneration after subtotal resection is inhibited by the use of new immunosuppressive drugs. Transplant Proc. 2002; 34(6): 2312-3.

21. Garcia-Criado FJ, Palma-Vargas JM, Valdunciel-Garcia JJ, Toledo AH, Misawaka K, Gomez-Alonso A, Toledo-Pereyra LH. Tacrolimus (FK506) down-regulates free radicals tissue levels, serum cytokines, and neutrophil infiltration after severe liver ischemia. Transplantation. 1997; 64(4): 594-8.

22. Brown DC, Gatter KC. Ki-67 protein: the immaculate deception? Histopathology. 2002; 40(1): 2-11.

23. Taub R. Liver regeneration 4: transcriptional control of liver regeneration. FASEB J. 1996; 10(4): 413-27.

24. White $\mathrm{P}$, Brestelli JE, Kaestner KH, Greenbaum LE. Identification of transcriptional networks during liver regeneration. J Biol Chem. 2005; 280(5):3715-22. Epub 2004 Nov 16. 
Recebido em 18/04/2009

Aceito para publicação em 27/06/2009

Conflito de interesse: nenhum

Fonte de financiamento: nenhuma

\section{Como citar este artigo:}

Gama Filho O, Toderke EL, Baretta GAP, Sakamoto DG, Agulham MA, Tambara EM, Matias JEF. Imunossupressão com tacrolimus favo- rece a regeneração hepática induzida por hepatectomia extensa em ratos. Rev Col Bras Cir. [periódico na Internet] 2010; 37(3). Disponível em URL: http://www.scielo.br/rcbc

\section{Endereço para correspondência:}

Ozimo Gama Filho

E-mail: ozimogama@hotmail.com 